\title{
Cerebrospinal fluid sodium rhythms
}

\author{
Michael G Harrington ${ }^{1 *}$, Ronald M Salomon², Janice M Pogoda ${ }^{3}$, Elena Oborina ${ }^{1}$, Neil Okey ${ }^{1}$, Benjamin Johnson ${ }^{2}$, \\ Dennis Schmidt ${ }^{2}$, Alfred N Fonteh", Nathan F Dalleska ${ }^{4}$
}

\begin{abstract}
Background: Cerebrospinal fluid (CSF) sodium levels have been reported to rise during episodic migraine. Since migraine frequently starts in early morning or late afternoon, we hypothesized that natural sodium chronobiology may predispose susceptible persons when extracellular CSF sodium increases. Since no mammalian brain sodium rhythms are known, we designed a study of healthy humans to test if cation rhythms exist in CSF.

Methods: Lumbar CSF was collected every ten minutes at $0.1 \mathrm{~mL} / \mathrm{min}$ for $24 \mathrm{~h}$ from six healthy participants. CSF sodium and potassium concentrations were measured by ion chromatography, total protein by fluorescent spectrometry, and osmolarity by freezing point depression. We analyzed cation and protein distributions over the $24 \mathrm{~h}$ period and spectral and permutation tests to identify significant rhythms. We applied the False Discovery Rate method to adjust significance levels for multiple tests and Spearman correlations to compare sodium fluctuations with potassium, protein, and osmolarity.

Results: The distribution of sodium varied much more than potassium, and there were statistically significant rhythms at 12 and $1.65 \mathrm{~h}$ periods. Curve fitting to the average time course of the mean sodium of all six subjects revealed the lowest sodium levels at $03.20 \mathrm{~h}$ and highest at $08.00 \mathrm{~h}$, a second nadir at $09.50 \mathrm{~h}$ and a second peak at $18.10 \mathrm{~h}$. Sodium levels were not correlated with potassium or protein concentration, or with osmolarity.

Conclusion: These CSF rhythms are the first reports of sodium chronobiology in the human nervous system. The results are consistent with our hypothesis that rising levels of extracellular sodium may contribute to the timing of migraine onset. The physiological importance of sodium in the nervous system suggests that these rhythms may have additional repercussions on ultradian functions.
\end{abstract}

\section{Background}

Many behaviorally related dynamical processes in the nervous system are characterized by episodes of complex oscillatory states whose periodicity may be expressed over multiple temporal and spatial scales [1]. Mood [2] and mania-like behavior [3] have been induced by disruption of the CLOCK gene, and a foodentrainable circadian rhythm was found to be regulated by a dorsomedial hypothalamic oscillator [4]. Intrinsic fluctuations within cortical systems account for variability in evoked brain responses [5], yet little is known of the chronobiology of many brain components and it is not known whether pathophysiological symptoms of many diseases are causally linked to circadian rhythms or to other diurnal behaviors [6].

\footnotetext{
* Correspondence: mghworks@hmri.org

${ }^{1}$ Molecular Neurology Program, Huntington Medical Research Institutes, Pasadena, CA, 91101, USA
}

Migraine commonly has an onset in early morning or late afternoon, suggesting an underlying biochemical rhythm may predispose to this temporal variability [7-11]. We discovered that CSF sodium concentration $\left(\left[\mathrm{Na}^{+}\right]_{\mathrm{cs}}\right)$ increased during migraine while blood plasma sodium concentration did not change [12]. $\left[\mathrm{Na}^{+}\right]_{\mathrm{csf}}$ is rapidly equilibrated with extracellular sodium concentration $\left(\left[\mathrm{Na}^{+}\right]_{\mathrm{e}}\right)$ [13-15] and we recently proposed a mechanism for the higher $\left[\mathrm{Na}^{+}\right]_{\mathrm{csf}}$ in migraine based on increased activity of capillary endothelial cell sodium potassium ATPase (NKAT) [16]. Many other chronobiological events may be involved in migraine onset, including serotonin that was shown to rise markedly at night in non-human primates, and is light regulated [17]. Many lines of evidence have implicated serotonin in migraine and serotonin agonists are in the front line of treatment [18]. Whatever the biochemical mechanism that determines migraine onset, we consider that a 
physiological rhythm change in $\left[\mathrm{Na}^{+}\right]_{\mathrm{csf} / \mathrm{e}}$ may contribute to the triggering of migraine.

Sodium is crucial for neuronal excitability and, since there are no published data on $\left[\mathrm{Na}^{+}\right]_{\mathrm{csf} / \mathrm{e}}$ chronobiology, we designed experiments in nonheadache-suffering volunteers to investigate whether there are any physiological rhythms of sodium in CSF. We predicted that a rising $\left[\mathrm{Na}^{+}\right]_{\mathrm{cs}}$ in the early morning and late afternoon would be a feature of normal brain sodium homeostasis if $\left[\mathrm{Na}^{+}\right]_{\mathrm{csf} / \mathrm{e}}$ change is relevant to migraine time of onset.

\section{Methods}

\section{Study participants}

Volunteer controls stated that they did not suffer from troublesome headaches or migraine, and had no family history of migraine. Potential participants were excluded if lumbar puncture could not be performed due to fever, bleeding disorder, coumadin treatment, pregnancy, or other acute medical conditions. Informed and signed consent was obtained as approved by the Vanderbilt University Institutional Review Board. Participants were not taking any medications, and had no psychiatric diagnoses based on the Structured Clinical Interview for DSM-IV Axis 1 Disorders, Non Patient Edition, and confirmed in a psychiatric diagnostic interview (by RMS). Physical exams and blood tests assured normal healthy status both pre- and post-study.

Participants abstained from caffeine for the three days prior to the study and were admitted in the evening and acclimated to the Vanderbilt General Clinical Research Center environment prior to CSF collections. Diet was caffeine free, monoamine-balanced, and consisted of 3 $4.5 \mathrm{~g}$ total daily sodium. Meals were served around $06.30 \mathrm{~h}$ and $10.00 \mathrm{~h}$, after which participants were fasted except for intravenous $5 \%$ dextrose at $125 \mathrm{~mL}$ per h, and drinking water ad libitum. Participants were supine overnight before catheter placement and throughout the 24-h collection. There were no compromises to this positioning: they were not allowed to sit up even briefly, or even lean up on an elbow; they were limited to one pillow; rotation was allowed 'on axis' since the catheter was taped to the skin up to the shoulder so that it would not get wound around the waist; toileting was urinal or bedpan, with no bedside commodes, and no ambulating. Participants were dorsal supine (lying on back) when eating, and raised their heads only. No bending of the bed was allowed, with no raising of the knee or back areas: this was mostly to encourage frequent position changes and minimize the risk of lower extremity deep venous thrombosis. Lights were out from $20.30 \mathrm{~h}$ to $06.00 \mathrm{~h}$. Daytime napping was discouraged. Catheters $(24 \mathrm{~g})$ were inserted at $07.00 \mathrm{~h}$ using a $20 \mathrm{~g}$ Touhy needle with standard local anesthesia by an anesthesiologist skilled in the procedure (BJ). CSF collection was initiated at $08.00 \mathrm{~h}$. Continuous flow collections were regulated by peristaltic pump, synchronized with a chilled-block fraction collector $\left(4^{\circ} \mathrm{C}\right)$ to accumulate $1 \mathrm{ml}$ samples every $10 \mathrm{~min}$. Samples were removed from the fraction collector, placed on dry ice within $30 \mathrm{~min}$ of collection, and stored at $-80^{\circ} \mathrm{C}$ until thawed for assays. All participants tolerated the procedure well.

\section{Protein assay}

Concentrations of protein in CSF were determined using a microplate-based Quant-iT protein assay kit (Invitrogen/Molecular Probes, Carlsbad, CA, USA) using bovine serum albumin (Sigma-Aldrich, St. Louis, MO, USA), 0$500 \mu \mathrm{g} / \mathrm{mL}$, as a standard. Briefly, $10 \mu \mathrm{L}$ aliquots of CSF or protein standard in triplicates was added to a 96-well microtiter plate. Quant-IT protein reagent was diluted in Quant-iT protein buffer and $200 \mu \mathrm{L}$ was added to each well. After 45 to $60 \mathrm{~min}$, the fluorescence (excitation/emission at $470 / 570 \mathrm{~nm}$ ) was measured using a Gemini XPS microplate reader (Molecular Devices, Sunnyvale, CA, USA) and protein concentrations in each sample were computed using Softmax software from Molecular Devices.

\section{Cation measurements}

CSF samples were thawed and $10 \mu \mathrm{L}$ was diluted by 1:1,000 CSF with Milli-Q ultra pure de-ionized water (Millipore, Billerica, MA), well mixed and transferred into $5 \mathrm{~mL}$ PolyVials with Filtercaps (DIONEX, Sunnyvale, CA). A Dionex AS 40 autosampler was used to transfer samples to a $25 \mathrm{uL}$ sample loop for injection, that were analysed in duplicate on a DIONEX DX500Ion Chromatography system to determine $\left[\mathrm{Na}^{+}\right]$and $\left[\mathrm{K}^{+}\right]$. The instrument is comprised of an IP25 isocratic pump, an EG40 eluent generator with a methyl sulfonic acid cartridge, an Ultra II cation self-regenerating suppressor (CSRS), and a CD 20 conductivity detector employing an un-thermostated conductivity detection cell. Analyses were performed on $4 \mathrm{~mm}$ diameter CG12A $(50 \mathrm{~mm})$ guardand CA12A $(250 \mathrm{~mm})$ analytical ion exchange columns with methysulfonic at $18 \mathrm{mM}$ (isocratic) and a flow rate of $1.0 \mathrm{~mL} / \mathrm{min}$. The CSRS was operated at $100 \mathrm{~mA}$. were injected by an AS40 autosampler from $5 \mathrm{~mL}$ vials with integral filter caps.

Sodium and potassium cations were calibrated (and continuously verified) with NIST-certified standard mixtures (SPEX CertiPrep, Metuchen, NJ, USA). Cation calibration curves were linear with correlation coefficients $>0.99$ for $\left[\mathrm{K}^{+}\right]$and $>0.995$ for $\left[\mathrm{Na}^{+}\right]$spanning the diluted concentrations of unknowns. Quality control standards were run every 25 samples to ensure accuracy of analysis (95-105\% recovery). Random samples were re-analyzed to check reproducibility. Chromatographic peaks were integrated using DIONEX PeakNet software and results plotted. CSF was run in duplicate and the 
results averaged for all samples. Any discrepancy between the two duplicate measures was re-analyzed until the deviation was overcome.

\section{Osmometry}

The osmolarity of $50 \mu \mathrm{L}$ of CSF was determined in a freezing point osmometer, the 5004 Micro-Osmette ${ }^{\text {rix }}$, calibrated with 100 and 500 mosmol reference standards (Precision Systems, Inc., Natick, MA, USA).

\section{Spectral analysis and statistics}

Descriptive statistics (means, standard deviations) and Spearman correlations (with confidence intervals [CI]) were performed using GraphPad Prism, MATLAB (Mathworks, Natick, MA, USA), or SAS version 9.2 (SAS Institute Inc., Cary, NC, USA). Linear regressions of total protein values over the $24 \mathrm{~h}$ were derived to determine their slopes and goodness of fit.

Spectral analyses were as follows. The average of the duplicate measures for each time-point were compiled for all 144 fractions, and the resultant time-course-spectrum was detrended (first order linear regression line removed to eliminate any global drift), and Hamming windowed (end-points moved towards zero to avoid Fourier artifacts from abrupt drop-offs) as preparation for the discrete Fourier transformation (DFT). Power spectral densities (PSDs) were plotted as the square of each coefficient. Average PSDs were calculated from the average of the six individual participants.

The permutation test [19] was done as follows. The raw time-series data were shuffled to produce 1000 random permutations; i.e., each frequency had 1000 random values drawn from the original time-series data. The DFT was applied to each random permutation and the PSD was derived for each. The $p$ value of each frequency of the PSD was the proportion of the 1000 random PSD magnitudes that was greater than the original magnitude at that frequency; i.e., how likely was it that that magnitude would have occurred by chance. The false discovery rate (FDR) method of significance level adjustment was used to control the type 1 errors. The FDR is defined as the expected proportion of erroneous rejections among the rejections; e.g., an FDR of 0.05 for a given PSD implies that $5 \%$ of rejections for that PSD are false.

\section{Results}

There were no adverse effects from the clinical procedures. The mean age of participants was $31.5 \pm 7.1 \mathrm{yr}$, with 2 males and 4 females. The mean 24-h CSF protein was $329 \pm 69 \mu \mathrm{g} / \mathrm{mL}$, sodium was $150.6 \pm 10.9 \mathrm{mM}$, potassium was $2.96 \pm 0.7 \mathrm{mM}$, and osmolarity was 355 $\pm 39.1 \mathrm{mOsmol}$.

The distributions of the $24 \mathrm{~h} \mathrm{CSF}\left[\mathrm{Na}^{+}\right]$and $\left[\mathrm{K}^{+}\right]$for all six participants (Figures 1 and 2) show that there was a much larger scatter for $\left[\mathrm{Na}^{+}\right]$than for $\left[\mathrm{K}^{+}\right]$. Our first concern regarded the method reproducibility, especially for $\left[\mathrm{Na}^{+}\right]$, because many points were out of the typical range for CSF (145 - $155 \mathrm{mM})$. Nevertheless, the reproducibility of the assays was clearly not limiting, as the SDs of the same CSF run ten times on different days $(1.9 \mathrm{mM}$ for $\mathrm{Na}, 0.2 \mathrm{mM}$ for $\mathrm{K}, 3.2 \mu \mathrm{g} / \mathrm{mL}$ total protein, and $1.53 \mathrm{mOsmol}$ ) was much less than the SDs of the 24-h measures. Thus although some $\left[\mathrm{Na}^{+}\right]$values are not in the typical range, we have confidence in the reproducibility of the assays.

Our next concern was whether the intrathecal catheters in these 1-day experiments would cause irritation that might be reflected in a rising total CSF protein (in an earlier experiment, a four day intrathecal catheter led to a rising total protein on days 3 and 4, unpublished data). However, there was no increase in protein, as seen in the non-significant slopes of the CSF 24-h total protein from all six participants (Figure 3).

Since the CSF $\left[\mathrm{Na}^{+}\right]$distribution varied considerably, and to test our main hypothesis, we plotted the 24-h spectrum for each participant individually (Figure 4). There is the appearance of rhythm in this profile, and we took three approaches to test this. Based on concern that some technical aspect of collection may have led to spurious fluctuations of $\left[\mathrm{Na}^{+}\right]$, we combined the data from all six participants (samples collected on different days) as described in the Methods, and plotted the results (Figure 5). Rather than cancelling out any spurious results, a convincing 12-h rhythm can be seen. In order to obtain an objective measure of the times of each peak and trough, we applied curve fitting and a $4^{\text {th }}$ degree polynomial gave an optimal fit. From this function, we identified the lowest $\left[\mathrm{Na}^{+}\right]$level $(\mathrm{C})$ at $03.20 \mathrm{~h}$ and the highest level (D) at $08.00 \mathrm{~h}$. A second nadir (A) occurred at $09.50 \mathrm{~h}$ and a second peak (B) at $18.20 \mathrm{~h}$ (Figure 5).

Furthermore to more rigorously test for rhythms in the 24-h CSF spectra, we applied DFT with permutation analysis as described in the Methods. Figure 6 displays the combined relative PSD profile from all six participants. Solid red circles represent significant rhythm periods at $24 \mathrm{~h}(p<0,001), 12 \mathrm{~h}(p=0.002), 1.7 \mathrm{~h}(p=$ $0.012)$ and $1.6 \mathrm{~h}(p=0.01)$. Since our sampling was only over a total of $24 \mathrm{~h}$, we have less confidence in the $24 \mathrm{~h}$ period than in the shorter periods. We consider the 1.7 and $1.6 \mathrm{~h}$ coefficients to be a single peak approximately $1.65 \mathrm{~h}$ (= $100 \mathrm{~min})$. Individual PSDs and permutation statistics are provided in Additional Files 1 (Six individual $\left[\mathrm{Na}^{+}\right]_{\mathrm{csf}}$ Power Spectral Densities) and 2 (Permutation analysis statistics of six individual $\left[\mathrm{Na}^{+}\right]_{\mathrm{csf}}$ Power Spectral Densities and their Average).

Because of concern that these apparent sodium rhythms may be correlated with changes in osmolarity or total protein, we determined Spearman correlation 


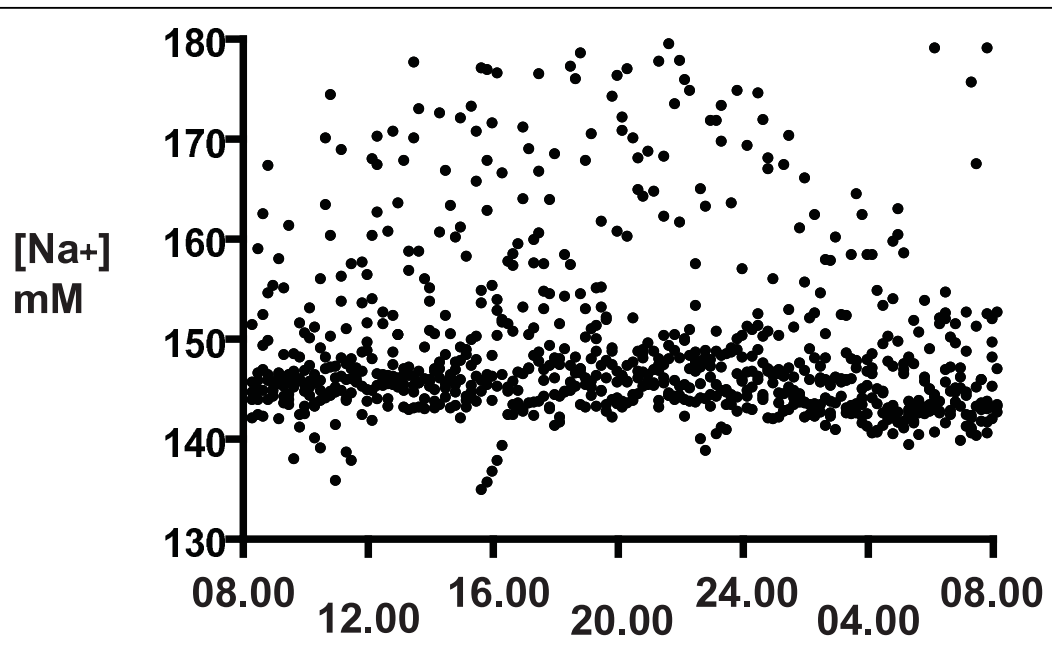

\section{Time of day}

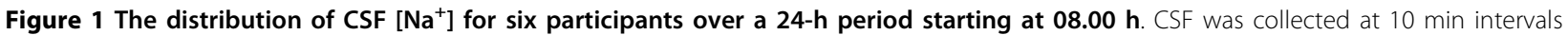
and $\left[\mathrm{Na}^{+}\right]$was determined by cation exchange liquid chromatography, as described in Methods. Samples were analyzed in duplicate and averaged (solid circles).

coefficients with $\mathrm{CI}$. For osmolarity/Na: $\mathrm{r}=-0.22(-0.37$, -0.06). For $\mathrm{Na}$ /protein: $\mathrm{r}=0.24(0.08,0.39)$. Based on these weak correlations, we can conclude the variables of osmolarity and total protein are not the cause of the sodium fluctuations.

Potassium levels had minimal change over $24 \mathrm{~h}$ (Figure 2). Since $\mathrm{Na}$ and $\mathrm{K}$ are co-transported by NKAT, we compared them to see if their changes were correlated. We would expect a negative correlation if these levels were primarily NKAT regulated. To the contrary, their Spearman correlation factor CI was positive, +0.71 (0.61, 0.78).

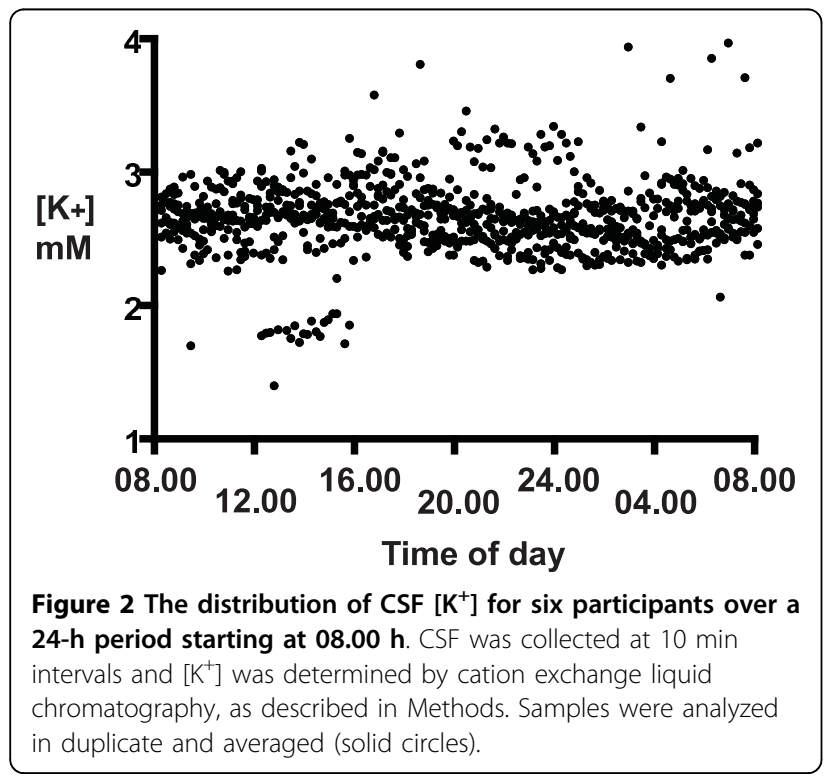

\section{Discussion}

This is the first reported data of CSF sodium chronobiology in the human nervous system showing that $[\mathrm{Na}$ ${ }^{+}$]csf has a $12 \mathrm{~h}$ rhythm that peaks around 08.00 and $18.10 \mathrm{~h}$ and troughs around 03.20 and $09.50 \mathrm{~h} .\left[\mathrm{Na}^{+}\right]_{\mathrm{csf}}$ also has a $100 \mathrm{~min}$ rhythm. The invasiveness of the procedure in humans has limited the sample size. However, we present evidence that the fluctuations we observed are biological because firstly, reproducibility was good and much less than for the 24-h sample variations. The measures of osmolarity at each time point were made on single assays, but the reproducibility of this assay was extremely good. Secondly, the cation calibration standards were used frequently to detect and correct for drift and thirdly, sodium rhythms were not significantly correlated with total protein or osmolarity. We interpret the lack of correlation with protein to exclude a mechanical inflammation that would have led to a rise of total protein. We interpret the lack of correlation with osmolarity to exclude any major evaporation or dehydration of samples.

Data from 144 samples per subject over $24 \mathrm{~h}$ allows rhythms at $20 \mathrm{~min}$ or greater to be detected. The principal rhythm with a 12-h period is visible in Figures $4 \& 5$. We have less confidence in the 24-h period, since this involved the entire time of our sampling. This would require further testing in a longer duration study. We did not confidently identify the other significant period at $1.65 \mathrm{~h}$ (100 $\mathrm{min}$ ) in the raw data (we were not looking for it), but it is significant in all the spectral analyses (Figure 6 and Additional Files 1 and 2). The primary 


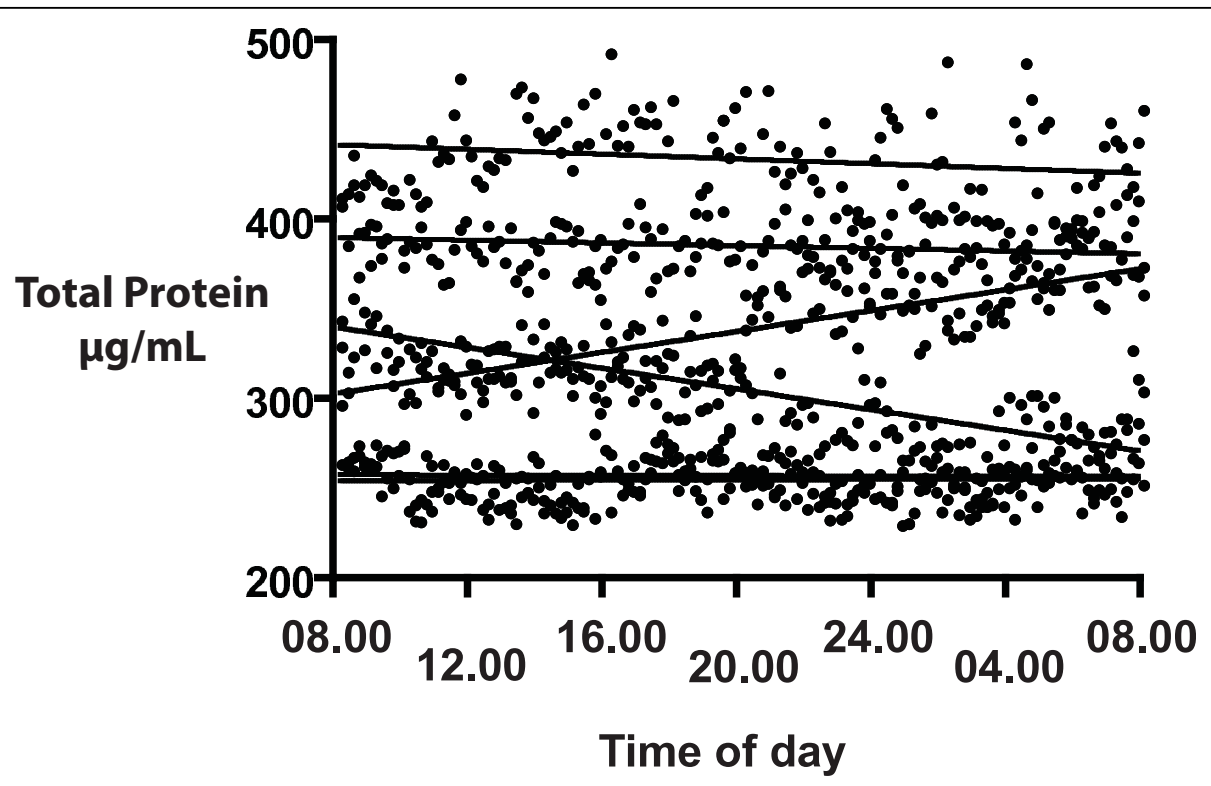

Figure $\mathbf{3}$ The distribution of CSF total protein over a $\mathbf{2 4 - h}$ period for six participants, starting at $\mathbf{0 8 . 0 0} \mathbf{h}$. CSF was collected at 10 min intervals and total protein was determined by fluorescent spectroscopy, as described in Methods. Samples were analyzed in duplicate and averaged (solid circles). The lines represent the slopes from linear regression for each of the six participants. There was no consistent trend with time.

source of sodium is dietary, but since the two meal times of these participants did not coincide with the principal 12- or 1.6-h cycles, their diet is not likely to be responsible for these rhythms.

In spite of these reassurances, this first report of CSF sodium chronobiology could reflect many other variables, as yet untested. Both a longer duration study, with more individuals, and with other species would be informative. Animal model systems, such as sheep or non-human primates, would be conducive to a more expansive study.

Although the fluctuations in $\mathrm{K}^{+}$were minimal, the positive instead of negative correlation of $\left[\mathrm{K}^{+}\right]$with $\left[\mathrm{Na}^{+}\right]$was surprising, since NKAT activity at the bloodbrain barrier should lead to an inverse relationship. We suggest that the positive correlation of $\mathrm{Na}+$ with $\mathrm{K}^{+}$

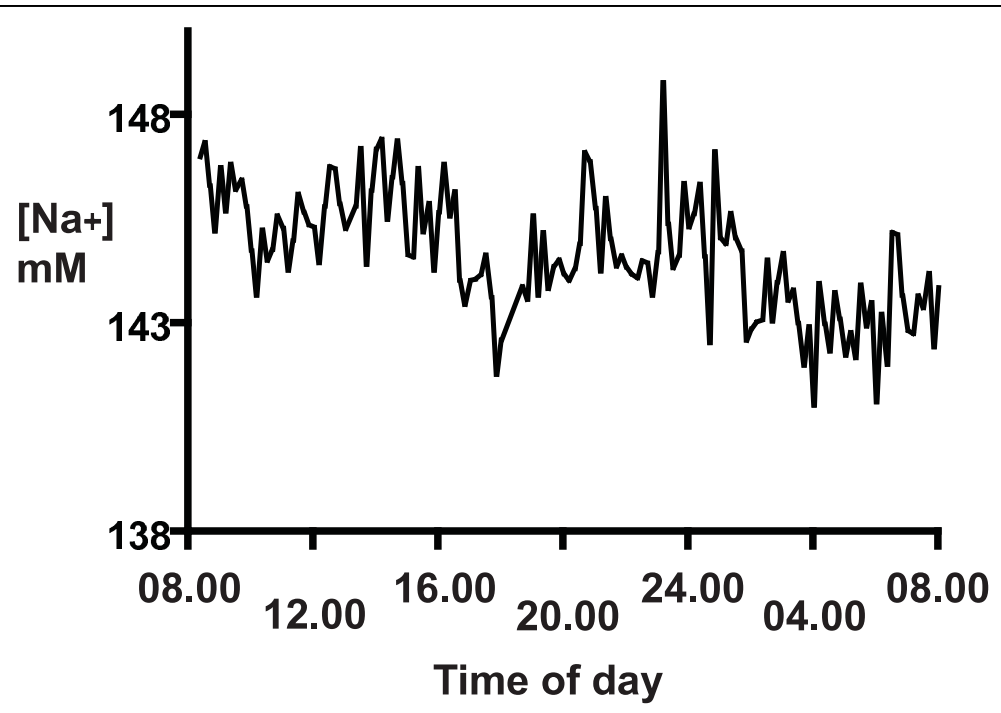

Figure 4 The distribution of $\mathrm{CSF}\left[\mathrm{Na}^{+}\right]$over a $24-\mathrm{h}$ period for one representative participant, starting at $08.00 \mathrm{~h}$. The data points in this case are connected by the line, and represent 144 samples measured in duplicate, as described in Methods. There appears to be rhythms in the spectrum, but they are hard to quantify. 


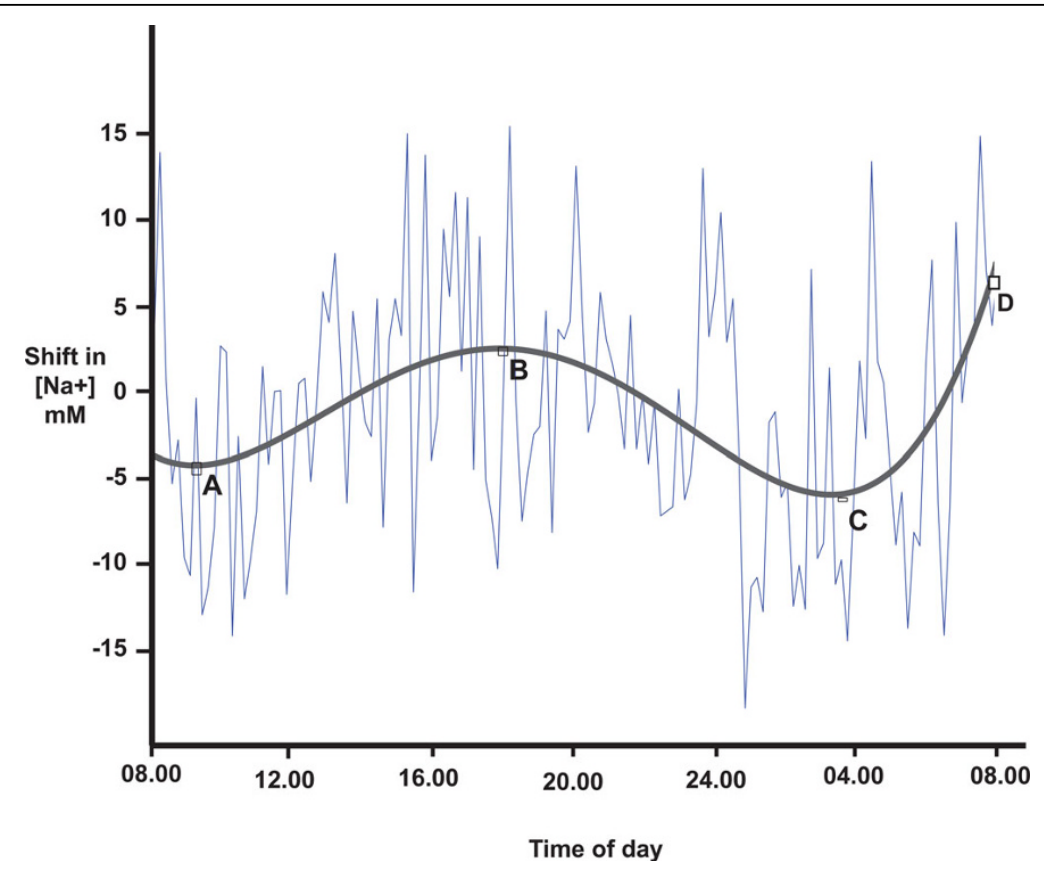

Figure 5 The $24 \mathrm{~h}$ mean rhythm of $\mathrm{CSF}\left[\mathrm{Na}^{+}\right]$for all six participants, plotted as a shift from the mean as described in the Methods Data were fitted with a $4^{\text {th }}$ degree polynomial curve to identify the peaks and troughs: A: $09.50 \mathrm{~h}, \mathrm{~B}: 18.10 \mathrm{~h}, \mathrm{C}: 03.20 \mathrm{~h}$, and D: $08.00 \mathrm{~h}$. The $12-$ hour rhythm is most clear.

could be a reflection of differences between their methods of regulation. We have proposed that capillary endothelial cell NKAT activity is the primary source for the overall higher $\left[\mathrm{Na}^{+}\right]$and lower $\left[\mathrm{K}^{+}\right]$in brain interstitial fluid compared to plasma[16]. However, brain tissue is more intolerant of changes in $\left[\mathrm{K}^{+}\right]$than $\left[\mathrm{Na}^{+}\right]$and will stabilize $\left[\mathrm{K}^{+}\right]$levels rapidly; for example, increased neuronal firing from elevated $\left[\mathrm{Na}^{+}\right]_{\mathrm{e}}$ may increase $\left[\mathrm{K}^{+}\right]_{\mathrm{e}}$, and active glial mechanisms effect local $\left[\mathrm{K}^{+}\right]$homeostasis to minimize these changes. To explain our current data, we propose that the cation levels derived from the brain interstitial fluid/capillary NKAT environment are modified by the time they reach the lumbar CSF. Thus the $\left[\mathrm{Na}^{+}\right]$changes are still evident while the brain tissue has stabilized the $\left[\mathrm{K}^{+}\right]$. This is reflected in our more dispersed $\left[\mathrm{Na}^{+}\right]$than $\left[\mathrm{K}^{+}\right]$data. Clearly, more experiments

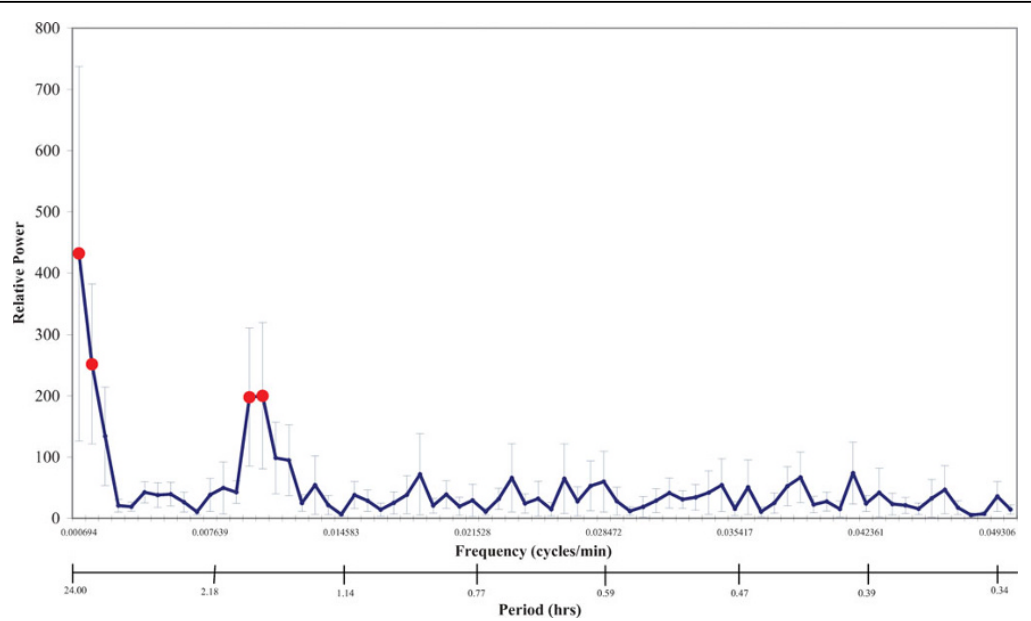

Figure 6 The Discrete Fourier Transform of the 24-h CSF $\left[\mathrm{Na}^{+}\right]$from six participants, combined and derived as described in the Methods. The average PSD is plotted against both the frequency (cycles/min) and the period (h), together with standard error bars. The averaged data reveal the common significant peaks in solid circles (determined by permutation statistics with FDR adjustment as described in Methods): $24.0 \mathrm{~h}(p<0.001), 12.0 \mathrm{~h}(p=0.002), 1.7 \mathrm{~h}(p=0.012)$, and $1.6 \mathrm{~h}(p=0.010)$. 
are required to investigate this dynamic cation biochemistry.

Sodium chronobiology has been studied in blood and urine from young, healthy volunteers and was shown to decrease from midnight to early morning [20-22]. Elderly healthy volunteers also had a similar circadian rhythm for blood sodium, though the amplitude of change was reduced compared to younger persons [23]. More frequent sampling in rats demonstrated increasing blood plasma sodium during sleep, with a decrease prior to waking [24]. These results suggest that brain/CSF sodium rhythms are differentially regulated from the systemic circulation. Furthermore, none of these blood plasma sodium references have 10 minute sampling similar to our study, precluding identification of shorter rhythms in these studies, such as the $1.65 \mathrm{~h}$ (100 min) -period that we identified in CSF.

The individual PSD analyses reveal individual variability (Additional File 1). We expect different people will have different rhythms and that these will fluctuate in individuals as sleep and other behaviors vary. We have confined our study to look for physiological rhythms that are reasonably common, because of the small number of participants. Hence our emphasis on the averaged PSDs that reveal overall common rhythms. A nocturnal rhythm was not surprising, since many analytes are known to change between sleep and wake states. The afternoon rise was perhaps less expected, since this has not been reported from previous studies of other CSF analytes. The shorter 1.65 -h period was least expected, but tissue rhythms of this time $(100 \mathrm{~min})$ are well known, and correspond both with the timing of known rhythms of biological events such as cognition [25] and sleep periods [26]) and, at a molecular level, with NKAT activity [27].

The regulation responsible for these CSF sodium rhythms is of interest. Sensory circumventricular organs are involved in brain homeostasis [28]. Subfornical organ $\mathrm{Na}_{\mathrm{x}}$ channels sense sodium, and osmolarity is assessed by transient receptor potential vanilloid type 1 channels in neuronal cells and volume-regulated anion channels in glial cells, both in the supraoptic and paraventricular nuclei [29]. Sodium Potassium ATPase (NKAT) is the principal regulator of $\left[\mathrm{Na}^{+}\right]$, consuming nearly one half of the energy of the brain [30], pumping $3 \mathrm{Na}^{+}$out of and $2 \mathrm{~K}^{+}$into cells. NKAT rhythms have been reported in the mammalian brain [27], and NKAT is clearly involved in $\left[\mathrm{Na}^{+}\right]_{\mathrm{csf}}$ regulation [31-33]. Our data does not reveal inverse changes of the $\mathrm{Na}^{+} / \mathrm{K}^{+}$that would be consistent with NKAT rhythms being the effector of our reported sodium rhythms and have provided an explanation for this discrepancy above. In addition, we cannot assess rhythms $<20$ min in duration, many other regulatory factors in brain tissue, or the effects of CSF circulation to the lumbar site of collection.

The change of CSF $\left[\mathrm{Na}^{+}\right]$that we report $(10 \mathrm{mM}$ from the data in Figure 5, and over $40 \mathrm{mM}$ in Figure 1) will reflect changes in brain sodium. Radioactive $\mathrm{Na}^{+}$distribution studies reveal that although $\left[\mathrm{Na}^{+}\right]_{\mathrm{csf}}$ is modified at different points along the neuraxis $[15,34]$, it is reasonable to assume it reflects $\left[\mathrm{Na}^{+}\right]_{e}$, since equilibration of $\left[\mathrm{Na}^{+}\right]_{\mathrm{e}}$ with lumbar CSF occurs rapidly [13-15]. We expect the changes in $\left[\mathrm{Na}^{+}\right]_{\mathrm{e}}$ may be greater in specific brain regions, since the samples obtained here will have been diluted with normal CSF before reaching the lumbar site of collection.

The magnitude of change of CSF $\left[\mathrm{Na}^{+}\right]$(mean shift of $10 \mathrm{mM}$ ) is sufficient to have physiological effect on neuronal excitability. Moreover, this data raises the possibility that efforts to reduce the natural sodium variation or to administer drugs to coincide with sodium chronobiology may reduce migraine in susceptible people. Hodgkin and Katz [35] demonstrated that the action potential rises at a rate roughly proportional to the rise of $\left[\mathrm{Na}^{+}\right]_{\mathrm{e}}$. When a neuron is at rest, the $\mathrm{Na}^{+}$influx through voltage-gated $\mathrm{Na}^{+}$channels is low, as these channels are usually closed or inactivated. However, the channel gate is displaced when $\left[\mathrm{Na}^{+}\right]_{\mathrm{e}}$ increases [36] Higher $\left[\mathrm{Na}^{+}\right]_{\mathrm{e}}$ speeded recovery from the inactivation state, enabling an earlier action potential and leading to hyperexcitability [36]. Higher $\left[\mathrm{Na}^{+}\right]_{\mathrm{cs}}$ caused a sympathetic hyperactivity response (increasing blood pressure and heart rate) through increasing ouabain-like substances and activating the brain renin-angiotensinaldosterone system $[37,38]$.

\section{Conclusion}

We tested the hypothesis that a natural rise of CSF sodium might trigger migraine onset in susceptible people and predicted a rise when migraine time of onset is most common. The identification of a $12-\mathrm{h} \mathrm{CSF} \mathrm{Na}^{+}$ rhythm (there is also a 100 min rhythm) in the early morning and late afternoon, the two most frequent times of migraine onset, supported this hypothesis. This correlation is not proof that the $\mathrm{Na}^{+}$rhythms trigger migraine onset, but is an observation that merits further study. This data raises the possibility that efforts to reduce the natural sodium variation or to administer drugs to coincide with sodium chronobiology may reduce migraine in susceptible people.

\footnotetext{
Additional file 1: Six individual $\left[\mathrm{Na}^{+}\right]_{\mathrm{csf}}$ Power Spectral Densities.

PSDs for six individual CSF spectra. Standard deviations are indicated by error bars. Relative power is plotted against the hourly period. Significant periods are determined by permutation assay as described in the Methods, and are indicated by solid circles. The differences in scale between individuals in their relative power on the $y$-axis is explained
} 
because the Fourier magnitude is unit-less and influenced mainly by magnitude. The shape of the curve is the most informative.

Click here for file

[http://www.biomedcentral.com/content/supplementary/1743-8454-7-3S1.PDF ]

Additional file 2: Permutation analysis statistics of six individual $\mathrm{INa}$ $\left.{ }^{+}\right]_{\text {csf }}$ Power Spectral Densities and their Average. Permutation analysis statistics of six individual $\left[\mathrm{Na}^{+}\right]_{\text {cff }}$ Power Spectral Densities and their Average.

Click here for file

[http://www.biomedcentral.com/content/supplementary/1743-8454-7-3S2.PDF ]

\section{Abbreviations}

CSF: Cerebrospinal fluid; CSRS: cation self-regenerating suppressor; DFT: discrete Fourier transformation; FDR: false discovery rate; $\left[\mathrm{Na}^{+}\right]_{\text {cff: }}$ sodium concentration in CSF; $\left[\mathrm{Na}^{+}\right]_{e}$ : sodium concentration in brain extracellular fluid; NKAT: $\mathrm{Na}^{+}, \mathrm{K}^{+}$, -ATPase transporter; PSD: power spectral density.

\section{Acknowledgements}

This research was supported at HMRI by the $\mathrm{NIH}$, the Norris, Lucas Brothers, Glide, and Hezlep foundations. GCRC work was supported in part by Vanderbilt CTSA grant 1 UL1 RR024975 from the National Center for Research Resources, National Institutes of Health. We are indebted to our study participants for their altruism.

\section{Author details}

'Molecular Neurology Program, Huntington Medical Research Institutes, Pasadena, CA, 91101, USA. ${ }^{2}$ Vanderbilt University School of Medicine, Nashville, TN, 37212, USA. ${ }^{3}$ Statology, Palm Desert, CA, 92260, USA.

${ }^{4}$ California Institute of Technology, Pasadena, CA 91125, USA.

\section{Authors' contributions}

MGH conceived and designed the project, analyzed all data, and wrote the initial manuscript. RMS designed the CSF collections, analyzed all data, and participated in manuscript revisions. JMP oversaw all statistical analyses, and participated in manuscript revisions. NFD and EO designed the ion chromatography methods and performed cation analyses. NO carried out cation analyses. BJ performed all intrathecal cannulations. DS carried out all preliminary CSF retrievals. ANF contributed to manuscript revisions. All authors read and approved the final manuscript.

\section{Competing interests}

The authors declare that they have no competing interests.

Received: 22 September 2009

Accepted: 20 January 2010 Published: 20 January 2010

\section{References}

1. Erchova I, McGonigle DJ: Rhythms of the brain: an examination of mixed mode oscillation approaches to the analysis of neurophysiological data. Chaos 2008, 18:015115.

2. Hampp G, Ripperger JA, Houben T, Schmutz I, Blex C, Perreau-Lenz S, Brunk I, Spanagel R, Ahnert-Hilger G, Meijer JH, Vitaterna MH, Orsulak P, Takahashi JS, Nestler EJ, Carlezon WA Jr, MCClung CA: Regulation of monoamine oxidase A by circadian-clock components implies clock influence on mood. Curr Biol 2008, 18:678-683.

3. Roybal K, Theobold D, Graham A, DiNieri JA, Russo SJ, Krishnan V, Chakravarty S, Peevey J, Oehrlein N, Birnbaum S, Vitaterna MH, Orsulak P, Takahashi JS, Nestler EJ, Carlezon WA Jr, McClung CA: Mania-like behavior induced by disruption of CLOCK. Proc Natl Acad of Sci USA 2007, 104:6406-6411.

4. Fuller PM, Lu J, Saper CB: Differential rescue of light- and foodentrainable circadian rhythms. Science 2008, 320:1074-1077.

5. Fox MD, Snyder AZ, Vincent JL, Raichle ME: Intrinsic fluctuations within cortical systems account for intertrial variability in human behavior. Neuron 2007, 56:171-184.
6. Klerman EB: Clinical aspects of human circadian rhythms. J Biol Rhythms 2005, 20:375-386.

7. Fox AW, Davis RL: Migraine chronobiology. Headache 1998, 38:436-441.

8. Alstadhaug KB, Bekkelund S, Salvesen R: Circannual periodicity of migraine?. Eur J Neurol 2007, 14:983-988.

9. Kelman L: Pain characteristics of the acute migraine attack. Headache 2006, 46:942-953.

10. Solomon GD: Circadian rhythms and migraine. Cleve Clin J Med 1992, 59:326-329.

11. Spierings EL, Sorbi M, Maassen GH, Honkoop PC: Psychophysical precedents of migraine in relation to the time of onset of the headache: the migraine time line. Headache 1997, 37:217-220.

12. Harrington MG, Fonteh AN, Cowan RP, Perrine K, Pogoda JM, Biringer RG, Huhmer AF: Cerebrospinal fluid sodium increases in migraine. Headache 2006, 46:1128-1135.

13. Bito LZ, Davson H: Local variations in cerebrospinal fluid composition and its relationship to the composition of the extracellular fluid of the cortex. Exp Neurol 1966, 14:264-280.

14. Olsen NS, Rudolph GG: Transfer of sodium and bromide ions between blood, cerebrospinal fluid and brain tissue. Am J Physiol 1955, 183:427-432.

15. Sweet WH, Brownell GL, Scholl JA, Bowsher DR, Benda P, Stickley EE: The formation, flow and absorption of cerebrospinal fluid; newer concepts based on studies with isotopes. Res Publ Assoc Res Nerv Ment Dis 1955, 34:101-159.

16. Harrington MG, Fonteh AN, Arakaki X, Cowan RP, Ecke LE, Foster $H$, Huhmer AF, Biringer RG: Capillary Endothelial $\mathrm{Na}(+), \mathrm{K}(+)$, ATPase Transporter Homeostasis and a New Theory for Migraine Pathophysiology. Headache 2009.

17. Garrick NA, Tamarkin L, Taylor PL, Markey SP, Murphy DL: Light and propranolol suppress the nocturnal elevation of serotonin in the cerebrospinal fluid of rhesus monkeys. Science 1983, 221:474-476.

18. Evers S, Afra J, Frese A, Goadsby PJ, Linde M, May A, Sandor PS: EFNS guideline on the drug treatment of migraine-revised report of an EFNS task force. Eur J Neurol 2009, 16:968-981.

19. Blackford JU, Salomon RM, Waller NG: Detecting change in biological rhythms: a multivariate permutation test approach to Fouriertransformed data. Chronobiol Int 2009, 26:258-281

20. Kawasaki T, Uezono K, Ueno M, Omae T, Matsuoka M, Haus E, Halberg F: Comparison of circadian rhythms of the renin-angiotensin-aldosterone system and electrolytes in clinically healthy young women in Fukuoka (Japan) and Minnesota (USA). Acta Endocrinol 1983, 102:246-251.

21. Sothern RB, Vesely DL, Kanabrocki EL, Bremner FW, Third JL, McCormick JB, Dawson S, Ryan M, Greco J, Bean JT, Nemchausky BM, Shirazi P, Scheving LE: Circadian relationships between circulating atrial natriuretic peptides and serum sodium and chloride in healthy humans. Am J Nephrol 1996, 16:462-470.

22. Baghdassarian RA, Aghadadian SN, Hairapetian TV, Yeghian VA, Burshtein GY, Filian JP: Comparative study of sodium, potassium, ionized calcium, urea and creatinine circadian rhythm documented in samples of capillary and venous blood from healthy subjects. Chronobiologia 1990, 17:15-25

23. Trotti R, Rondanelli M, Cuzzoni G, Magnani B, Gabanti E, Ferrari E: Circadian organization of serum electrolytes in physiological aging. Funct Neuro 2003, 18:77-81.

24. Fang Z, Carlson SH, Peng N, Wyss JM: Circadian rhythm of plasma sodium is disrupted in spontaneously hypertensive rats fed a high-NaCl diet. $\mathrm{Am}$ J Physiol Regul Integr Comp Physio 2000, 278:R1490-1495.

25. Klein $R$, Armitage $R$ : Rhythms in human performance: 1 1/2-hour oscillations in cognitive style. Science 1979, 204:1326-1328.

26. Othmer E, Hayden MP, Segelbaum R: Encephalic cycles during sleep and wakefulness in humans: a 24-hour pattern. Science 1969, 164:447-449.

27. Wang HY, Huang RC: Diurnal modulation of the $\mathrm{Na}+/ \mathrm{K}+-\mathrm{ATP}$ ase and spontaneous firing in the rat retinorecipient clock neurons. $J$ Neurophysiol 2004, 92:2295-2301.

28. Johnson AK, Gross PM: Sensory circumventricular organs and brain homeostatic pathways. Faseb J 1993, 7:678-686.

29. Orlov SN, Mongin AA: Salt-sensing mechanisms in blood pressure regulation and hypertension. Am J Physiol Heart Circ Physiol 2007, 293: H2039-2053. 
30. Whittam $R$ : The dependence of the respiration of brain cortex on active cation transport. Biochem J 1962, 82:205-212.

31. Damkier HH, Prasad V, Hubner CA, Praetorius J: Nhe1 is a luminal $\mathrm{Na}+/ \mathrm{H}+$ exchanger in mouse choroid plexus and is targeted to the basolateral membrane in Ncbe/Nbcn2-null mice. Am J Physiol Cell Physiol 2009, 296 : C1291-1300.

32. Praetorius J: Water and solute secretion by the choroid plexus. Pflugers Arch 2007, 454:1-18.

33. Amin MS, Reza E, Wang $\mathrm{H}$, Leenen FH: Sodium transport in the choroid plexus and salt-sensitive hypertension. Hypertension 2009, 54:860-867.

34. Somjen GG: Neuroglia and spinal fluids. J Exp Biol 1981, 95:129-133.

35. Hodgkin AL, Katz B: The effect of sodium ions on the electrical activity of giant axon of the squid. J Physiol 1949, 108:37-77.

36. Kuo CC, Liao SY: Facilitation of recovery from inactivation by external $\mathrm{Na}$ + and location of the activation gate in neuronal $\mathrm{Na}+$ channels. J Neurosci 2000, 20:5639-5646.

37. Van Huysse JW, Hou X: Pressor response to CSF sodium in mice: mediation by a ouabain-like substance and renin-angiotensin system in the brain. Brain Res 2004, 1021:219-231.

38. Huang BS, Amin MS, Leenen FH: The central role of the brain in saltsensitive hypertension. Curr Opin Cardiol 2006, 21:295-304.

doi:10.1186/1743-8454-7-3

Cite this article as: Harrington et al:: Cerebrospinal fluid sodium rhythms. Cerebrospinal Fluid Research 2010 7:3.

Publish with Bio Med Central and every scientist can read your work free of charge

"BioMed Central will be the most significant development for disseminating the results of biomedical research in our lifetime. "

Sir Paul Nurse, Cancer Research UK

Your research papers will be:

- available free of charge to the entire biomedical community

- peer reviewed and published immediately upon acceptance

- cited in PubMed and archived on PubMed Central

- yours - you keep the copyright 